\title{
Successful transfer to sulfonylurea therapy in an infant with developmental delay, epilepsy and neonatal diabetes (DEND) syndrome and a novel $A B C C 8$ gene mutation
}

\author{
N. Zwaveling-Soonawala • E. E. Hagebeuk • \\ A. S. Slingerland • C. Ris-Stalpers • T. Vulsma • \\ A. S. van Trotsenburg
}

Received: 4 August 2010 / Accepted: 22 October 2010 /Published online: 26 November 2010

(C) The Author(s) 2010. This article is published with open access at Springerlink.com

Keywords $A B C C 8 \cdot$ Developmental delay $\cdot$ Infantile spasms $\cdot \mathrm{K}_{\mathrm{ATP}} \cdot$ Neonatal diabetes mellitus $\cdot$ Sulfonylurea

$\begin{array}{ll}\text { Abbreviations } \\ \text { DEND } & \begin{array}{l}\text { Developmental delay, epilepsy } \\ \text { and neonatal diabetes }\end{array} \\ \text { PNDM } & \begin{array}{l}\text { Permanent neonatal diabetes mellitus } \\ \text { SDS }\end{array} \\ \text { SUR(1/2) } & \text { Standard deviation score } \\ & \text { Sulfonylurea receptor }(1 / 2)\end{array}$

To the Editor: Permanent neonatal diabetes mellitus (PNDM) is mainly caused by activating mutations in the $K C N J 11$ or $A B C C 8$ genes, encoding respectively the Kir6.2

\footnotetext{
N. Zwaveling-Soonawala $(\bowtie) \cdot T$. Vulsma

A. S. van Trotsenburg

Department of Pediatric Endocrinology,

Emma Children's Hospital, Academic Medical Centre,

PO Box 22660, 1100 DD, Amsterdam, The Netherlands

e-mail: n.zwaveling@amc.uva.nl

E. E. Hagebeuk

Department of Pediatric Neurology, Emma Children's Hospital,

Academic Medical Centre,

Amsterdam, The Netherlands
}

A. S. Slingerland

Institute of Biomedical and Clinical Sciences,

Peninsula Medical School,

Exeter, UK

C. Ris-Stalpers

Laboratory of Pediatric Endocrinology,

Emma Children's Hospital, Academic Medical Centre,

Amsterdam, The Netherlands and sulfonylurea receptor (SUR)1 subunits of the $\mathrm{K}_{\mathrm{ATP}}$ channels in the pancreatic beta cells [1-3]. Developmental delay, epilepsy and neonatal diabetes syndrome (DEND) represents the most severe clinical form of PNDM [4]. Besides diabetes mellitus patients exhibit severe developmental delay, hypotonia and therapy-resistant epilepsy. As $K C N J 11$ and $A B C C 8$ are expressed in neuronal tissue the neurological features in DEND syndrome are postulated to result from mutated $\mathrm{K}_{\mathrm{ATP}}$ channels in the brain. Only a few cases of DEND syndrome have been described. More common is a milder clinical picture, without generalised epilepsy and with less severe developmental delay, referred to as intermediate DEND.

Since 2006 many patients with PNDM due to KCNJ11 and $A B C C 8$ mutations have been completely transferred from insulin to sulfonylurea drugs $[5,6]$. However, in DEND syndrome only cases of intermediate DEND were sulfonylurea-responsive [7, 8]. Shimomura and colleagues reported the first patient with severe DEND syndrome, due to a KCNJ11 mutation, who did completely switch to sulfonylurea drugs [4]. Here we report a case of DEND syndrome due to a novel $A B C C 8$ mutation and successful transfer to sulfonylurea treatment.

A boy was born as second child of non-consanguineous white parents following an uneventful pregnancy and spontaneous term delivery. His birthweight was low $(2,700 \mathrm{~g},-2$ standard deviation score [SDS]). At 7 weeks of age he presented with failure to thrive (weight $3,140 \mathrm{~g},-3.8 \mathrm{SDS}$ ), severe hyperglycaemia (blood glucose $42 \mathrm{mmol} / \mathrm{l}$ ), glucosuria, and ketoacidosis. Physical examination revealed severe generalised hypotonia without dysmorphic features or other abnormalities. Islet cell auto antibodies, serum insulin and Cpeptide were undetectable. Abdominal ultrasound examina- 
tion demonstrated a normally developed pancreas. Neonatal diabetes mellitus was concluded and continuous intravenous insulin therapy was started followed by continuous subcutaneous insulin pump therapy. This resulted in good glycaemic control without significant hypoglycaemia. At the age of 5 months $\mathrm{HbA}_{1 \mathrm{c}}$ was $7.2 \%$ and catch-up growth (weight -2 SDS) was observed.

On the tenth day of admission, at the age of 2 months, he developed frequent subtle seizures unresponsive to increasing doses of the anti-epileptic drug phenobarbital. EEG examination showed a burst-suppression pattern (abnormal for the age of 8.5 weeks) and epileptic discharges later on. At the age of 3 months the seizures progressed to infantile spasms and EEG examination demonstrated a slowed high-voltage background pattern with multifocal epileptic discharges consistent with hypsarrhythmia and unresponsive to various antiepileptic drugs (phenobarbital, nitrazepam, adrenocorticotropic hormone and vigabatrin). At age 5 months the boy was severely hypotonic, with no visual contact, no babbling, hardly any facial expression and a psychomotor developmental age of 1 month. Magnetic resonance imaging of the brain at that age demonstrated no structural abnormalities but mild atrophy of frontal-temporal regions. DEND syndrome was suspected and the boy was tested for $\mathrm{K}_{\text {ATP }}$ channel defects. Genomic DNA isolated from peripheral lymphocytes was analysed by direct sequencing of all coding sequences as well as the relevant intron/exon boundaries. The KCNJ11 sequence was wild type. In exon 1 of the $A B C C 8$ gene a monoallelic missense mutation was present $(\mathrm{c} .145 \mathrm{~A}>\mathrm{T})$ that changed amino acid residue 49 from isoleucine to phenylalanine (p. I49F). This nucleotide change was not previously reported in any single-nucleotide polymorphism or mutation database, was absent in 70 control alleles and also absent in genomic DNA from both parents, indicating a de novo mutation.

In an attempt to influence both glycaemic control and neurological abnormalities, at the age of 5.5 months oral glibenclamide therapy was started in a daily dose of $0.2 \mathrm{mg} / \mathrm{kg}$ body mass in two doses followed by weekly increments of $0.2 \mathrm{mg} / \mathrm{kg}^{-1} \mathrm{day}^{-1}$. The insulin dose could gradually be reduced and after 2 months, at a glibenclamide dose of $1.6 \mathrm{mg} / \mathrm{kg}$, insulin therapy was stopped. Side effects of glibenclamide treatment were not noticed, and there were no episodes of hypoglycaemia. Gradually the daily glibenclamide dose was tapered and at the age of 17 months he continued to have excellent glycaemic control with $1.0 \mathrm{mg} / \mathrm{kg}\left(\mathrm{HbA}_{1 \mathrm{c}}\right.$ $5.6 \%)$. No improvement was observed in seizure control despite anti-epileptic drug treatment with high dose vigabatrin and levetiracetam. At the age of 26 months his functional psychomotor age was 3 months and he continued to have infantile spasms with unchanged EEG hypsarrhythmia.
To our knowledge, this is the first report of a DEND patient with an $A B C C 8$ mutation who successfully transfers to sulfonylurea therapy. Although functional studies were not performed the mutation is likely to be the molecular origin of the patient's DEND syndrome, as it is a de novo mutation in a child of unaffected parents and affects an amino acid residue that shows evolutionary conservation across species. Based on the topology suggested by Conti and colleagues, amino acid residue 49 is located either in the $\mathrm{N}$-terminal extracellular region or in the first predicted transmembrane domain [9]. The in silico prediction programs SIFT and PolyPhen both predicted that substitution at position 49 from isoleucine to phenylalanine would affect protein function. The excellent response to sulfonylurea treatment provides further evidence for the pathogenicity of the mutation.

Shimomura and colleagues reported the first patient with severe DEND syndrome, due to a KCNJ11 mutation, who completely switched to sulfonylurea drugs [4]. Their patient also showed neurological improvement on a dose of $2.3 \mathrm{mg} / \mathrm{kg}$, suggesting that such extremely high doses might influence neurological symptoms. In our case glucose values dropped to $3.5 \mathrm{mmol} / \mathrm{l}$ with a sulfonylurea dose of $1.6 \mathrm{mg} / \mathrm{kg}$ and further increasing the sulfonylurea dosage was thought to be contraindicated by the risk of hypoglycaemia. As the main aim in the treatment of DEND syndrome is to influence neurological dysfunction, perhaps increasing sulfonylurea doses should have been considered together with an additional treatment to prevent hypoglycaemia. Furthermore it could be speculated that rather than a drug that targets both SUR1 and SUR2 isoforms, such as glibenclamide, a SUR1-specific drug, such as gliclazide, might influence neurological symptoms more effectively as only SUR1 isoforms are present in neuronal $\mathrm{K}_{\mathrm{ATP}}$ channels. It is not clear to what extent sulfonylurea drugs are hindered by the blood-brain barrier. Administering sulfonylurea drugs at a very young age, when the blood-brain barrier is still immature, might lead to better brain penetration than at later ages.

This case report emphasises the importance of early genetic analysis in all cases of neonatal diabetes mellitus, including the most severely affected patients with DEND syndrome as in this group, sulfonylurea treatment may also completely restore glucose homeostasis. The effect on neurological features is a field of future research perhaps aiming at improved blood-brain barrier penetrance of sulfonylurea drugs and allowing higher doses by alternatively handling hypoglycaemia.

Acknowledgement We thank I. Bertram and J. de Randamie for technical assistance. 
Duality of interest statement The authors declare that there is no duality of interest associated with this manuscript.

Open Access This article is distributed under the terms of the Creative Commons Attribution Noncommercial License which permits any noncommercial use, distribution, and reproduction in any medium, provided the original author(s) and source are credited.

\section{References}

1. Gloyn AL, Pearson ER, Antcliff JF et al (2004) Activating mutations in the gene encoding the ATP-sensitive potassiumchannel subunit Kir6.2 and permanent neonatal diabetes. N Engl J Med 350:1838-1849

2. Babenko AP, Polak M, Cavé $H$ et al (2006) Activating mutations in the ABCC8 gene in neonatal diabetes mellitus. $\mathrm{N}$ Engl J Med 355:456-466

3. Proks P, Arnold AL, Bruining J et al (2006) A heterozygous activating mutation in the sulphonylurea receptor SUR1 (ABCC8) causes neonatal diabetes. Hum Mol Genet 15:1793-1800
4. Shimomura K, Horster F, de Wet H et al (2007) A novel mutation causing DEND syndrome; a treatable channelopathy of pancreas and brain. Neurology 69:1342-1349

5. Pearson ER, Flechtner I, Njølstad PR et al (2006) Switching from insulin to oral sulfonylureas in patients with diabetes due to Kir6.2 mutations. N Engl J Med 355:467-477

6. Rafiq M, Flanagan SE, Patch AM, Shields BM, Ellard S, Hattersley AT (2008) Effective treatment with oral sulfonylureas in patients with diabetes due to sulfonylurea receptor 1 (SUR1) mutations. Diab Care 31:204-209

7. Slingerland AS, Nuboer R, Hadders-Algra M, Hattersley AT, Bruining GJ (2006) Improved motor development and good long-term glycemic control with sulfonylurea treatment in a patient with the syndrome of intermediate developmental delay, early-onset generalised epilepsy and neonatal diabetes associated with the V59M mutation in the KCNJ11 gene. Diabetologia 49:2559-2563

8. Slingerland AS, Hurkx W, Noordam K et al (2008) Sulfonylurea therapy improves cognition in a patient with V59M KCNJ11 mutation. Diabet Med 25:277-281

9. Conti LR, Radeke CM, Shyng SL, Vandenberg CA (2001) Transmembrane topology of the sulfonylurea receptor SUR1. J Biol Chem 276:41270-41278 